\title{
Pulmonary Lesions and Serum Levels of Soluble Fas (SCD95) in Former HARD COAL MiNERS
}

\author{
F. Hoffmeyer, J. Henry, G. Borowitzki, R. Merget, J. Bünger, T. Brüning, M. Raulf-Heimsoth \\ Institute for Prevention and Occupational Medicine of the German Social Accident Insurance (IPA), Institute of the Ruhr-University, \\ Bochum, Germany
}

\begin{abstract}
Objective: Fas/APO-1 (CD95) and Fas Ligand (FasL) is a major mediator system that activates programmed cell death (apoptosis) and is most important for pulmonary cellular homeostasis. Another form of Fas, circulating soluble Fas (sCD95), produced by alternative mRNA splicing antagonizes the cell-surface Fas function. It was the aim of the study to test the hypothesis that the Fas/FasL system is implicated in the development of silica-induced pulmonary nodular lesions.

Material and methods: We investigated the serum levels of sCD95 in 55 former hard coal miners. Coal workers' pneumoconiosis (CWP) was assumed when the profusion of small round opacities according to the ILO 2000 classification system was 1/1 or greater. Analyses of sCD95 were performed by a sandwich ELISA.

Results: Radiologic CWP was found in 34 of the 55 individuals. The age of subjects with and without CWP was similar (73.5 (SD 7.2) years vs. 73.5 (7.1) years; $\mathrm{P}=0.924)$. $\mathrm{sCD} 95$ could be quantified in all samples; significantly higher levels were observed in subjects with radiologic signs of CWP (914 (752-1251) $\mathrm{pg} / \mathrm{ml} v$ s. 632 (509-804) pg/ml, $\mathrm{P}<0.001)$. However, there was no relationship between sCD95 serum concentrations and the quantity of profusion according to ILO.

Conclusions: The hypothesis of elevated sCD95 concentrations in CWP was corroborated. The usefulness of sCD95 for prevention and diagnosis of CWP and other forms of silica-induced fibrosis needs to be established by epidemiological studies.
\end{abstract}

Key words: Coal workers pneumoconiosis, silicosis, Fas, Fas ligand, hard coal miners

\section{INTRODUCTION}

The respiratory system represents the route of entry for many environmental and occupational pollutants. Accumulation of respirable silica particles can lead to a chronic lung disease characterized by granulomatous and fibrotic lesions. These processes may partly be triggered by the specific size and surface properties of the silica particles themselves but are amplified by inflammatory cells [1]. The initial inflammatory response is mediated by pulmonary macrophages activated after ingestion of silica particles. Activated macrophages release various inflammatory mediators including reactive oxygen species and attract neutrophils and lymphocytes thereby promoting alveolitis and tissue destruction [2]. Apoptosis, a tightly regulated form of programmed cell death, plays a pivotal role in tissue renewal and immune regulation and is mediated by Fas/Fas ligand (FasL) interaction [3]. Fas (CD95) belongs to the tumour necrosis factor (TNF) receptor family and is expressed in lymphocytes and bronchiolar and alveolar epithelial cells. CD95 is one of the most important receptors mediating T-cell dependent autoimmunity. In patients with silicosis a dysregulation of autoimmunity was observed leading to disorders such as rheumatic arthritis, systemic sclerosis or systemic lupus erythematosus [4].

Another form of Fas, circulating soluble Fas (sCD95), produced by alternative mRNA splicing and secreted from the cells can antagonize the cell-surface Fas function by blocking the binding of FasL [5]. Thus, elevated sCD95 levels inhibit Fas-mediated apoptosis and may offer a survival advantage to cells. An elevation of sCD95 levels in serum [6] and a dominant expression of sCD95 mRNA [7] were demonstrated in cases of silicosis without autoimmune diseases or malignant tumours. All cases were Japanese exposed to quartz dust [8].

Inhalative exposure to silica can result in different pathologic varieties and clinical presentations [9]. Simple nodular silicosis is the most common form of silicosis. Findings can vary due to the special conditions of exposure [10]. In hard coal miners there is a co-exposure of silica and coal dust and typical pathological findings are the deposition of coal dust and its association with airway obstruction and focal emphysema. Therefore, this entity is separated from silicosis in some countries and referred to as coal workers' pneumoconiosis (CWP). Apart from the occupational history, the diagnoses of silicosis and CWP are based on a chest radiograph demonstrating characteristic lesions which might be confirmed by high-resolution computed tomography [11]. 
Immune cells are widely considered as key components of silicosis [12]. However, endothelial cells and fibroblasts may also play a fundamental role in the pathogenesis of lung remodelling in pneumoconiosis especially concerning the development of fibrosis [13]. Turnover and activation of fibroblasts are important for extracellular matrix remodelling and are under control of apoptosis $[14,15]$. As apoptosis plays a pivotal role in cellular homeostasis and immune regulation and is mediated by Fas/Fas ligand (FasL) interaction, we tested the hypothesis that soluble Fas is implicated in the development of silica-induced pulmonary lesions.

\section{MATERIAL AND METHODS}

\section{Study Population}

The study was approved by a local Ethics Committee and all participants gave written informed consent. Serum samples were obtained from 55 male individuals who were examined for a medical expert opinion regarding CWP. They had worked as hard coal miners for $10 \mathrm{yr}$ or more. All subjects underwent questionnaire, evaluation of lung function and chest X-ray on the same day.

\section{LUNG FUNCTION}

Spirometry was performed according to the American Thoracic Society criteria (ATS) [16]. Forced vital capacity (FVC) and forced expiratory volume in $1 \mathrm{sec}$ (FEV1) were obtained from three acceptable lung function manoeuvres. Airways obstruction was defined as FEV1 $<80 \%$ predicted and a FEV1/FVC ratio $<70 \%$. Body plethysmography was used for calculating total lung capacity (TLC). The diffusing capacity carbon monoxide (TLCO) was measured with the single breath method [17]. All measurements were performed with a MasterLab pro (Software version 4.67a, Cardinal Health, Hoechberg, Germany).

\section{RADIOLOGY}

The radiographs were classified by experienced physicians. Only small nodules were considered for classification of CWP. The physicians had no prior knowledge about the subjects. Standard high kilovoltage postero-anterior and lateral chest films at maximum inspiration were made for each worker and CWP was diagnosed according to the classification of the International Labor Organization [11] with findings classified $1 / 1$ or greater. In case of CWP, severity was stratified according to the ILO 2000 classification system (CS) in different groups: CS-1: profusion $1 / 1$ or 1/2; CS-2: $2 / 1,2 / 2$ and $2 / 3$ and CS-3: $3 / 2,3 / 3$ and $3 /+$.

\section{SOLUble FAs (SCD95) ANALysis}

The serum samples were blind-coded before the determination of the sCD95 concentrations using a sandwich ELISA kit (Bender MedSystems, Vienna, Austria). Briefly, $100 \mu \mathrm{l}$ of diluted serum (1:10) were incubated in a Microwell Plate coated with monoclonal an- tibody to human sAPO-1/Fas. Then a biotin-conjugated anti-human sAPO-1/Fas antibody was added and after incubation and washing the sample was treated with Streptavidin-HRP. The reaction was terminated by addition of acid and absorbance was read at 450 $\mathrm{nm}$. Sample concentrations were calculated by interpolation of optical density (OD) values on a 4-parameter fitted standard curve, using Softmax Pro 4.7.1 (Molecular Devices, CA, USA). The range for quantification human sAPO-1/Fas was defined by the lower and upper level of the standard; between 16 and $1000 \mathrm{pg} / \mathrm{ml}$. The calculated overall coefficients of variation for intra-assay and inter-assay reproducibility were $4.0 \%$ and $12 \%$, respectively.

\section{STATISTICAL ANALYSIS}

Value distribution was assessed using the D'Agostino and Pearson omnibus normality test. Comparisons of unpaired data were performed with unpaired t-test and Welch`s correction, where appropriate. The data were analysed by using GraphPad Prism version 5.01 for Windows (GraphPad Software, San Diego, CA, www.graphpad.com). A two-sided significance level of 0.05 was chosen for all tests. Data were expressed as medians with interquartile ranges or as means with SD, where appropriate. Correlations between sCD95 and lung function parameters were calculated with Spearman's rank test.

\section{RESULTS}

\section{Clinical Data}

Radiologic CWP was diagnosed in 34 of the 55 individuals. The age of subjects with and without CWP was similar (mean $73.5 \pm 7.2$ vs. $73.5 \pm 7.1$ years; $\mathrm{P}=$ 0.924). Lung function data in the CWP categories are depicted in Table 1. In workers without CWP two groups could clearly be distinguished due to the smoking history. Smokers $(n=7)$ and non-smokers $(n=14)$ without CWP were of similar age (mean $72.9 \pm 10.4 v s$. $73.6 \pm 5.8)$ years; $\mathrm{P}=0.895)$, FEV1 was significantly lower in smokers (median $46.2(36.3-67)$ vs. 70.9 (63.6-87.1) \% predicted; $\mathrm{P}=0.014)$.

\section{sCD95 ANALYSIS}

All samples demonstrated concentrations in the linear range of the assay. Significantly higher serum sCD95 concentrations were measured in the coal miners with radiologic CWP (914 (752-1251) pg/ml) than in workers without CWP (632 (509-804) pg/ml, P<0.001) (Fig. 1A). There was no difference in the serum concentrations of sCD95 between the CWP severity grades (Fig. 1B). While FEV1\% predicted was significantly different between smoking and nonsmoking individuals, there was no difference in sFas concentrations (533 (503-780) vs. 634 (509-793); $\mathrm{P}=$ 0.751).

No obvious relationship between sCD95 concentrations and lung function could be revealed. There was only a tendency for a negative correlation between sCD95 concentrations and total lung capacity $(r=-$ $0.19, \mathrm{P}=0.08)$. 
Table 1. Lung function data in coal workers' pneumoconosis.

\begin{tabular}{|c|c|c|c|c|c|}
\hline & Without CWP & With CWP & Category Score- 1 & Category Score- 2 & Category Score- 3 \\
\hline $\mathrm{n}$ & 21 & 34 & 14 & 15 & 5 \\
\hline Age (yr) & $73.5 \pm 7.2$ & $73.5 \pm 7.1$ & $71.2 \pm 6.9$ & $75.7 \pm 5.5$ & $73.5 \pm 10.8$ \\
\hline FVC (\%pred) & $\begin{array}{c}87.1 \\
(77.0-96.2)\end{array}$ & $\begin{array}{c}91.9 \\
(79.8-107.4)\end{array}$ & $\begin{array}{c}90.1 \\
(75.2-98.7)\end{array}$ & $\begin{array}{c}95.0 \\
(74.6-111.2)\end{array}$ & $\begin{array}{c}105.0 \\
(87.3-119.8)\end{array}$ \\
\hline FEV1 (\%pred) & $\begin{array}{c}66.1 \\
(46.3-73.7)\end{array}$ & $\begin{array}{c}78.1 \\
(50.0-92.3)\end{array}$ & $\begin{array}{c}78.9 \\
(62.9-85.7)\end{array}$ & $\begin{array}{c}73.4 \\
(47.4-87.6)\end{array}$ & $\begin{array}{c}92.2 \\
(69.6-101.0)\end{array}$ \\
\hline FEV1/FVC (\%) & $\begin{array}{c}53.2 \\
(49.0-62.9)\end{array}$ & $\begin{array}{c}56.4 \\
(49.7-64.4)\end{array}$ & $\begin{array}{c}63.7 \\
(53.9-65.1)\end{array}$ & $\begin{array}{c}57.2 \\
(50.8-63.9)\end{array}$ & $\begin{array}{c}61.7 \\
(50.1-71.6)\end{array}$ \\
\hline TLC (\%pred) & $\begin{array}{c}100.1 \\
(90.8-120.1)\end{array}$ & $\begin{array}{c}96.1 \\
(80.5-107.4)\end{array}$ & $\begin{array}{c}97.9 \\
(84.5-106.9)\end{array}$ & $\begin{array}{c}94.0 \\
(78.8-109.0)\end{array}$ & $\begin{array}{c}103.0 \\
(79.6-110.0)\end{array}$ \\
\hline TLCO (\%pred) & $\begin{array}{c}66.3 \\
(54.2-75.5)\end{array}$ & $\begin{array}{c}62.2 \\
(44.8-73.7)\end{array}$ & $\begin{array}{c}62.1 \\
(47.4-76.9)\end{array}$ & $\begin{array}{c}60.6 \\
(40.6-70.9)\end{array}$ & $\begin{array}{c}78.0 \\
(62.1-86.3)\end{array}$ \\
\hline
\end{tabular}

Data are expressed as arithmetic means \pm SD for age and medians (interquartile ranges) for lung function parameters. FVC $=$ forced vital capacity; FEV1 = forced expiratory volume in $1 \mathrm{~s}$; TLC = total lung capacity; TLCO = diffusing capacity for carbon monoxide.

A

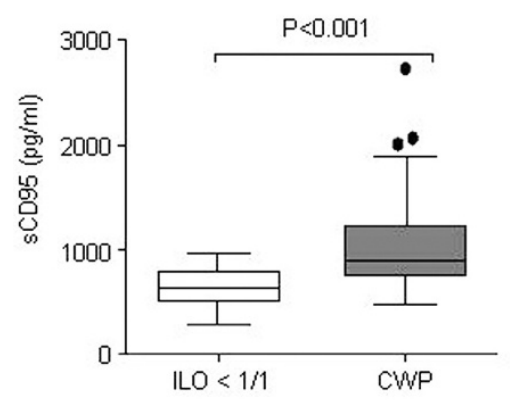

DisCUSSION

Increased exposure to coal mine dust containing silica particles results in the development of nodular lesions that contain heavily coal dust-laden macrophages interlaced with a fibrotic stroma evolving from inflammatory changes, cell proliferation, and excessive deposition of collagen and other extracellular matrix components by mesenchymal cells [10]. These nodular lesions are the basis for diagnosis of pneumoconiosis (silicosis/ CWP) by using chest X-ray [11]. There are marked differences in susceptibility of miners exposed to equal dust types and concentrations, and CWP affects only a minor percentage of exposed subjects [18].

In our study, chest X-ray classified pneumoconiosis with a profusion of at least $1 / 1$ according to the ILO classification system were seen in 34 workers [11]. The remaining 21 individuals with underground exposure and of similar age but without CWP served as reference group. We demonstrated higher sCD95 concentrations in former hard coal miners with radiologic pneumoconiosis with high statistical significance.

Our results are in line with findings of elevated sCD95 levels in Japanese patients with silicosis [6, 19]. We point to the ethnic background as the severity of pneumoconiosis and the development of autoimmune diseases might be influenced by differences in environmental or genetic factors [20]. Similar to our study analyses were performed with a sandwich ELISA. However, our monoclonal antibody based assay was much more sensitive $(13.2 \mathrm{pg} / \mathrm{ml}$ vs. $2 \mathrm{ng} / \mathrm{ml})$, and measured concentrations were all within the linear part of the standard curve.

Interestingly, the severity of CWP according to the ILO classification system was not associated with the level of sCD95 in serum. However, it should be noted that there is evidence that both inflammation and fibrosis persist after cessation of exposure and that the triggering of these processes is of the utmost importance. Individuals with pneumoconiosis after quartz exposure (silicosis/CWP) show various immunological abnormalities, and studies suggest the involvement of apoptosis pathways $[1,8]$. Apoptosis, a tightly regulated form of programmed cell death, plays a pivotal role in immune regulation, tissue renewal and cellular homeostasis. A major activation signal is mediated by Fas/APO-1 (CD95) and Fas ligand (FasL) interaction. It was demonstrated that in individuals with silicosis, the alternative mRNA splicing product $\mathrm{sFas}$ was expressed to a much higher degree than $\mathrm{mFas}$ [7]. Corre- 
spondingly, the same group detected elevated sFas levels in cases with silicosis even in the absence of autoimmune diseases [6]. Elevation of sFas can competitively inhibit membrane Fas/Fas ligand binding and consequently may offer a survival advantage to cells [3].

There is evidence that phagocytosis of apoptotic cells contributes to the resolution of inflammation. Concerning neutrophils, one should keep in mind that apoptosis is a form of cell death without or with a minimal inflammatory response in contrast to necrosis. In this line, impairment of apoptosis might result in an enhanced release of pro-inflammatory cytokines and proteolytic enzymes as well as reactive oxygen species [21]. While T-lymphocytes, alveolar macrophages and neutrophils are viewed as pivotal, other cell types like epithelial and mesenchymal cells are also implicated in the development of fibrosis [13 -15]. Apoptosis is the most important for pulmonary cellular homeostasis and has been shown to be responsible for the remodelling of certain mesenchymal cells like alveolar type II epithelial cells, endothelial cells, myofibroblasts, and fibroblasts during the repair phase [22]. Because hyperproliferation is also a hallmark of silica-induced nodular lesions we hypothesize that the triggering mechanisms for apoptosis are down-regulated in this chronic disease.

For prevention of CWP in hard coal miners and possibly other forms of pneumoconioses or fibrosis, it may be attractive to identify subjects at greater risk for pneumoconiosis. Our results add data confirming the importance of apoptosis in modulating the inflammatory response. The usefulness of sCD95 for prevention, but also diagnosis of CWP, needs to be established by epidemiological studies.

Conflicts of interests: There are no conflicts of interest or sponsorships declared by the authors in relation to this article.

\section{REFERENCES}

1. Huaux F. New developments in the understanding of immunology in silicosis. Curr Opin Allergy Clin Immunol 2007; 7: 168-73.

2. Hoffmeyer F, van Kampen V, Brüning T, Merget R. Pneumoconiosis. Pneumologie 2007; 61: 774-93 (Article in German).

3. DosReis GA, Borges VM, Zin WA. The central role of Fas-ligand cell signaling in inflammatory lung diseases. J Cell Mol Med 2004; 8: 285-93.

4. Jodo S, Kobayashi S, Kayagaki N, Ogura N, Feng Y, Amasaki Y, Fujisaku A, Azuma M, Yagita H, Okumura K, Koike T. Serum levels of soluble Fas/APO-1 (CD95) and its molecular structure in patients with systemic lupus erythematosus (SLE) and other autoimmune diseases. Clin Exp Immunol 1997; 107: 89-95.

5. Cheng J, Zhou T, Liu C, Shapiro JP, Brauer MJ, Kiefer MC, Barr PJ, Mountz JD. Protection from Fas-mediated apoptosis by a soluble form of the Fas molecule. Science 1994; 263: 1759-62.

6. Tomokuni A, Aikoh T, Matsuki T, Isozaki Y, Otsuki T, Kita S, Ueki H, Kusaka M, Kishimoto T, Ueki A. Elevated soluble Fas/APO-1 (CD95) levels in silicosis patients without clinical symptoms of autoimmune diseases or malignant tumours. Clin Exp Immunol 1997; 110: 303-9.
7. Otsuki T, Sakaguchi H, Tomokuni A, Aikoh T, Matsuki T, Kawakami Y, Kusaka M, Ueki H, Kita S, Ueki A. Soluble Fas mRNA is dominantly expressed in cases with silicosis. Immunology 1998; 94: 258-62.

8. Otsuki T, Miura Y, Nishimura Y, Hyodoh F, Takata A, Kusaka M, Katsuyama H, Tomita M, Ueki A, Kishimoto T. Alterations of Fas and Fas-related molecules in patients with silicosis. Exp Biol Med 2006; 231: 522-33.

9. Rimal B, Greenberg AK, Rom WN. Basic pathogenetic mechanisms in silicosis: Current understanding. Curr Opin Pulm Med 2005; 11: 169-73.

10. Mossman BT, Churg A. Mechanisms in the pathogenesis of asbestosis and silicosis. Am J Respir Crit Care Med 1998; 157: 1666-80.

11. International Labour Organization (ILO) guidelines for the use of the ILO international classification of radiographs of pneumoconioses. Revised edition. Geneva, Switzerland: ILO Publications, 2000

12. Otsuki T, Maeda M, Murakami S, Hayashi H, Miura Y, Kusaka M, Nakano T, Fukuoka K, Kishimoto T, Hyodoh F, Ueki A, Nishimura Y. Immunological effects of silica and asbestos. Cell Mol Immunol 2007; 4: 261-8.

13. Barbarin V, Xing Z, Delos M, Lison D, Huaux F. Pulmonary overexpression of IL-10 augments lung fibrosis and TH2 responses induced by silica particles. Am J Physiol Lung Cell Mol Physiol 2005; 288: 841-8.

14. Bühling F, Wille A, Rocken C, Wiesner O, Baier A, Meinecke I, Welte T, Pap T. Altered expression of membrane-bound and soluble CD95/Fas contributes to the resistance of fibrotic lung fibroblasts to FasL induced apoptosis. Respir Res 2005; 6: 37.

15. Drakopanagiotakis F, Xifteri A, Polychronopoulos V, Bouros D. Apoptosis in lung injury and fibrosis. Eur Respir J 2008; 32: 1631-8.

16. American Thoracic Society. Standardization of spirometry, 1994 Update. Am J Respir Crit Care Med 1995; 152: 1107-36.

17. Cotes JE, Chinn DJ, Quanjier PH, Roca J, Yernault JC. Standardization of the measurement of transfer factor (diffusing capacity). Report working party standardization of lung function tests, European Community for Steel and Coal. Official statement of the European Respiratory Society. Eur Respir J 1993; 6: 41-52.

18. Bourgkard E, Bernadac P, Chau N, Bertrand JP, Teculescu D, Pham Q. Can the evolution to pneumoconiosis be suspected in coal miners? A longitudinal study. Am J Respir Crit Care Med 1998; 158: 504-9.

19. Yuan BJ, Liu ZZ, Ding XR, Zou JM. Levels and clinic significance of serum soluble Fas and soluble Fas ligand in coal workers' pneumoconiosis. Zhonghua Lao Dong Wei Sheng Zhi Ye Bing Za Zhi 2006; 24: 96-8 (Article in Chinese).

20. Honda K, Kimura A, Dong RP, Tamai H, Nagato H, Nishimura Y, Sasazuki T. Immunogenetic analysis of silicosis in Japan. Am J Respir Cell Mol Biol 1993; 8: 106-11.

21. Haslett C. Granulocyte apoptosis and its role in the resolution and control of lung inflammation. Am J Respir Crit Care Med 1999; 160: 5-11.

22. Bardales RH, Xie SS, Schaefer RF, Hsu SM. Apoptosis is a major pathway responsible for the resolution of type II pneumocytes in acute lung injury. Am J Pathol 1996; 149: $845-52$.

\section{Address for correspondence:}

Frank Hoffmeyer

Institute for Prevention and Occupational Medicine

of the German Social Accident Insurance

Institute of the Ruhr-University, Bochum (IPA), Germany.

Phone: +49 (0)234 302-4549

Fax: +49 (0)234 302-4542

E-mail: hoffmeyer@ipa-dguv.de 